\title{
Quality of Life of Nephrotics Children and Its Related Factors
}

\author{
Sudung O. Pardede, Putri Maharani Tristanita Marsubrin", Rini Sekartini, Zakiudin Munasir \\ Departement of Child Health, Faculty of Medicine, Universitas Indonesia-Cipto Mangunkusumo Hospital, Jakarta, Indonesia \\ *Corresponding author: putristanita2806@yahoo.com \\ Received January 03, 2019; Revised February 05, 2019; Accepted March 08, 2019
}

\begin{abstract}
Background: Nephrotic syndrome (NS) is a common kidney disease found in children. Its medical and psychosocial complications can affect the quality of life (QoL). The aim of this study was to have a description on the QoL and its related factors using Pediatric Quality of Life Inventory ${ }^{\mathrm{TM}}$ (PedsQL ${ }^{\mathrm{TM}}$ ). Methods: An analytical descriptive study was conducted on patients, aged 2-18 years old in the outpatient and inpatient ward of nephrology, Department of Child Health, Dr. Cipto Mangunkusumo Hospital, Jakarta, during April 2013-December 2013. The assessment of QoL used PedsQL ${ }^{\mathrm{TM}} 4.0$ Chi-square test was performed to get variable with $\mathrm{p}$ value $<0.25$ which subsequently included in multivariate analysis. Logistic regression was performed to find factors associated with QoL. Unpaired t test was performed to find correlation between length of illness and QoL. Results: 100 NS patients were participated in this study and 19\% was found having disturbance in the QoL. Risk factors of disturbance in QoL were: age 5-7 years old, age 13-18 years old, low socio-economic status, father with low education level, and the use of steroid $(\mathrm{p}<0.05)$. Duration of illness was related to QoL based on parents and children reports $(\mathrm{p}<0.05)$, as well as child-rearing pattern. Conclusions: 19\% of NS had disturbance in QoL. The risk factors were children age, low socio-economic and low level education of parents, unexpected child-rearing pattern, duration of illness, and the use of steroid.
\end{abstract}

Keywords: Nephrotic syndrome, QoL, Peds $Q L^{T M}$, child-rearing pattern

Cite This Article: Sudung O. Pardede, Putri Maharani Tristanita Marsubrin, Rini Sekartini, and Zakiudin Munasir, "Quality of Life of Nephrotics Children and Its Related Factors." American Journal of Clinical Medicine Research, vol. 7, no. 1 (2019): 31-36. doi: 10.12691/ajcmr-7-1-6.

\section{Introduction}

Nephrotic syndrome (NS) is a common kidney disease found in children. Nephrotic syndrome consist of massive proteinuria ( $>40 \mathrm{mg} / \mathrm{m}^{2} \mathrm{BSA} /$ day), hypoalbuminemia $(<2,5 \mathrm{~g} / \mathrm{dL})$, oedema, and hypercholesterolemia $(>200 \mathrm{mg} / \mathrm{dL})$. The main therapy of NS is steroid, and based of response to steroid therapy, NS can be divided into sensitive steroid NS, frequent relapse NS, dependent steroid NS, and resistant steroid NS [1,2]. In Indonesia, NS was found 6 per 100,000 per year in children under 14 years of age, and in the Department of Child Health Dr. Cipto Mangunkusumo Hospital, during the period of 2009-2010, it was found 104 children with NS attended nephrology outpatient ward [2]. Children with chronic kidney disease (CKD) such as NS need special diet arrangement and lifestyle modification, monitoring by medical team on cardiovascular and physical complications, neurological developmental disorder, and psychosocial problems that will affect their quality of life (QoL) [3]. Significant psychosocial burden would not only affect the patients but also their family and caregiver [4]. Other factors affecting the QoL was child-rearing pattern which is important in the survival of the child because it is related to the family, environment, and nurturing environment of the child [5]. There are some methods to examine QoL such as Child Health Questionnaire (CHQ), German Generic Quality of Life Instrument for Children, and Pediatric Quality of Life Inventory (PedsQL). The Pediatric Quality of life Inventory is an instrument to measure the QoL that has good reliability and could be used for children age 2 until 18 years old. The aim of the study was to discover the association of demographic factors and QoL of children with NS, and the role of clinical response and duration of illness for QoL of children with NS.

\section{Methods}

This is an analytical descriptive study with cross sectional design conducted on the nephrology outpatient and inpatient ward Department of Child Health, Dr. Cipto Mangunkusumo Hospital, Jakarta during the period of April 2013-December 2013. The subjects of the study were all NS patients age 2-18 years old and have been diagnosed for more than 6 months. Patients with mental retardation and cerebral palsy were excluded. Minimal sample size was determined based on single sample proportional counts which come out with estimation of 96 subjects. Quality of life in children with nephrotic syndrome 
was examined by using PedsQL ${ }^{\mathrm{TM}}$ according to clinical response and time needed until diagnosis was established.

Parents from children that enrolled in this study were given explanation about the course of the research. The parents were asked for their consent to participate in the study. There are two questionnaires used in this study: the PedsQL ${ }^{\mathrm{TM}}$ (consists of parents and children reports), for PedsQL ${ }^{\mathrm{TM}}$ questionnaire, the parent's questionnaires were filled by parents. The children's questionnaires were filled by children if they were over 7 years old, and for children with age 5-7 years old, the parents assisted children to fill the questionnaire. Child-rearing pattern was examined by using child-rearing pattern questionnaire (KPAA-Kuesioner Pola Asuh Anak).

In this study, remission referred to reduction in proteinuria ( $<4 \mathrm{mg} / \mathrm{m}^{2} / \mathrm{h}$ or negative or trace) for three consecutive days, relapse: recurrence of severe proteinuria ( $>40 \mathrm{mg} / \mathrm{m}^{2} /$ hour or urine albumin dipstick $>2+$ ) for three consecutive days. Sensitive NS referred to patients who enter remission in response to corticosteroid treatment alone. Dependent steroid NS referred to patients respond to initial steroid treatment by developing complete remission, but develop a relapse either while still receiving steroids or within 2 weeks of discontinuation of treatment. Resistant steroid NS referred to patients who failure to achieve remission after 4 weeks of daily therapy with oral prednisone at a dose $2 \mathrm{mg} / \mathrm{kgbw} /$ day [2]. Children's education referred to none, pre-school, low level (primary to junior high school), mid level (high school). QoL is classified as high or low score. Higher score indicates good QoL, meaning there is no disturbance of QoL, and lower score indicates disturbed QoL [6]. Duration of illness means the duration since the diagnosed of NS was established until the study. Parent's educational level was divided into three types: (1) basic: graduated from primary to junior high school; (2) intermediate: graduated from high school; (3) advance: graduated from university. Parent's job was divided into employee and unemployed. According to Jakarta's minimum regional wage (MRW), socioeconomic level was divided into: below MRW and appropriate to MRW. Data were processed using the Statistical Package for the Social Sciences (SPSS) for Windows version 20.0. Univariate analysis showed the descriptive results of multiple variables. Bivariate analysis using chi-square was used to obtain variable with $\mathrm{p}<0.25$ which would further be analyzed in the multivariate analysis. Multivariate analysis was done using logistic regression to detect several factors that were related to the children's QoL. Unpaired t-test was done to analyze the relation between the duration of disease and the QoL. The protocol of this study has been approved by Medical Ethic Committee of Faculty of Medicine Universitas Indonesia, Dr. Cipto Mangunkusumo Hospital. (Letter No. 907/H2.F1/ETIK/IX/2013).

\section{Results}

There were 100 subjects with completed data that met the requirement for analysis. Subjects consists of 77 boys and 23 girls. Thirty-two subjects under 5 years old were not able to fill in the children reports, so there were 68 children followed the children's report. Forty-six percent of children had basic education, $61 \%$ father and $48 \%$ mother had mid level education. There were $92 \%$ employed father and $26 \%$ employed mother. There were $57 \%$ parents with mild to low socio-economic status with total family income under the minimum regional wage (MRW). On 65\% subjects, the researcher found an unexpected child-rearing pattern. There were 82 children with steroid therapy and 18 children without steroid therapy. Among children with steroid therapy, there were 50 sensitive steroid NS, 26 dependent steroid NS, and 24 resistant NS.

During the process of filling in the questionnaire, no difficulties were found from both parents and children. This study showed a disturbed QoL based on parents and children report as much as $19 \%$. The parents reports showed the relation between QoL and children's age and family income; and no significant association with children's gender, children's educational level, birth order, number of children, child-rearing pattern, father's and mother's educational level, father's and mother's job. (Table 1) And on children's report, there was relation between QoL and father's education, and no significant association was found between QoL and children's gender, age and education; birth order, number of children, child-rearing pattern, mother's education, father's and mother's job, and socio-economic status. (Table 2) Parents reports showed a significant association between the age of 5-7 years old and 13-18 years old with the QoL ( $\mathrm{p}<0.05$ ), that means the children's age is a risk factor to a disturbed QoL.

\subsection{Association between NS Therapy and QoL}

There were $82 \%$ of subjects still used steroid and 50\% were sensitive to steroid. On parents report, the using of steroid was related to the QoL (Table 3), but not in children's report (Table 4).

\subsection{Association between Duration of Illness and QoL}

The relation between duration of illness and QoL showed that on the parent's report, mean difference of duration of illness was -0,18 (CI 95\%, -0,37; -0,00) and $\mathrm{p}=0,048$, while on children's report the mean difference was $-0,22$ (CI 95\% -0,37; -0,07) and $\mathrm{p}=0,004$. Average duration of illness was 2 years and 8 months (7 months - 15 year and 8 months). Duration of illness had a significant association with a disturbance in QoL based on parents and children's report $(\mathrm{p}<0.05)$.

\subsection{Multivariate Analysis towards the QoL Related to Parents and Children's Reports}

Variables with p value $<0.25$ in bivariate analysis were counted in multivariate analysis. On the parents reports, the variables include in multivariate analysis were children's age, children's education, father's education, and total family income. Response to steroid, even with 
p value $>0.25$, theoretically has an association with QoL, therefore was counted in the multivariate analysis. The results of multivariate analysis which could be maintained in the parents reports consist of 2 variables, total family income $(2,74$, CI95\% 0,$80 ; 1,07)$ and response to steroid (0,59, CI95\% 0,18; 1,99).

On the children's reports, the variables include in the multivariate analysis were number of children, child-rearing pattern, father's education, mother's education, mother's job, and total family income. The results of multivariate analysis which could be maintained in the children's reports consist of 2 variables, child-rearing pattern (PR 3,61 CI95\% 0,69; 18,62) and total family income (PR 0,71 CI 95\% 0,30; 5,73).

Table 1. The association between demographic factors and QoL of NS children based on parents report

\begin{tabular}{|c|c|c|c|c|}
\hline \multirow{2}{*}{ Characteristics } & \multicolumn{2}{|c|}{ QoL (n=100) } & \multirow{2}{*}{ PR (CI 95\%) } & \multirow{2}{*}{ p value } \\
\hline & Not disturbed & Disturbed & & \\
\hline \multicolumn{5}{|l|}{ Sex: } \\
\hline Boys & 61 & 16 & Reference & \\
\hline Girls & 20 & 3 & $0,56(0,16-2,17)$ & 0,41 \\
\hline \multicolumn{5}{|l|}{ Children's age: } \\
\hline 2-4 years old & 30 & 2 & Reference & \\
\hline 5-7 years old & 23 & 8 & $5,22(1,01-26,95)$ & $0,04^{*}$ \\
\hline 8-12 years old & 20 & 5 & $3,75(0,66-21,25)$ & 0,13 \\
\hline 13-18 years old & 8 & 4 & $7,5(1,16-48,56)$ & $0,03^{*}$ \\
\hline \multicolumn{5}{|l|}{ Children's education: } \\
\hline None & 19 & 2 & Reference & \\
\hline Pre-school & 21 & 7 & $3,17(0,58-17,15)$ & $0,18^{* *}$ \\
\hline Low level & 37 & 9 & $2,31(0,45-11,78)$ & 0,31 \\
\hline Mid level & 4 & 1 & $2,37(0,17-32,99)$ & 0,51 \\
\hline \multicolumn{5}{|l|}{ Birth order: } \\
\hline First & 40 & 11 & Reference & \\
\hline Not first & 41 & 8 & $0,70(0,25-1,94)$ & 0,50 \\
\hline \multicolumn{5}{|l|}{ Number of children: } \\
\hline 2 children & 51 & 13 & Reference & \\
\hline > 2 children & 30 & 6 & $0,78(0,26-2,28)$ & 0,65 \\
\hline \multicolumn{5}{|l|}{ Child-rearing pattern: } \\
\hline Expected & 27 & 8 & Reference & \\
\hline Unexpected & 54 & 11 & $1,45(0,52-4,03)$ & 0,47 \\
\hline \multicolumn{5}{|l|}{ Father's education: } \\
\hline Advanced & 16 & 1 & Reference & \\
\hline Intermediate & 46 & 15 & $5,21(0,63-42,71)$ & $0,12 * *$ \\
\hline Basic & 19 & 3 & $2,52(0,23-26,72)$ & 0,44 \\
\hline \multicolumn{5}{|l|}{ Mother's education: } \\
\hline Advanced & 14 & 3 & Reference & \\
\hline Intermediate & 40 & 8 & $0,93(0,21-4,01)$ & 0,92 \\
\hline Basic & 27 & 8 & 1,38 (0,31-6,04) & 0,66 \\
\hline \multicolumn{5}{|l|}{ Father's job: } \\
\hline Employed & 79 & 18 & Reference & \\
\hline Unemployed & 2 & 1 & $2,19(0,18-25,54)$ & 0,53 \\
\hline \multicolumn{5}{|l|}{ Mother's job: } \\
\hline Employed & 22 & 4 & $1,39(0,41-4,67)$ & \\
\hline Unemployed & 59 & 15 & Reference & 0,58 \\
\hline \multicolumn{5}{|l|}{ Total family income: } \\
\hline Appropriate to MRW & 39 & 4 & Reference & \\
\hline Below MRW & 42 & 15 & $3,48(1,06-11,39)$ & $0,03 *$ \\
\hline
\end{tabular}

Note: PR: prevalence ratio; CI: confidence interval; *: $\mathrm{p}<0,05 ; * *$ : variables were included in multivariate analysis. 
Table 2. The association between demographic factors and QoL of NS children based on children report

\begin{tabular}{|c|c|c|c|c|}
\hline \multirow{2}{*}{ Characteristics } & \multicolumn{2}{|c|}{ QoL (n=68) } & \multirow{2}{*}{ PR (CI 95\%) } & \multirow{2}{*}{ p value } \\
\hline & Not disturbed & Disturbed & & \\
\hline \multicolumn{5}{|l|}{ Sex: } \\
\hline Boys & 38 & 15 & Reference & \\
\hline Girls & 11 & 4 & $0,92(0,25-3,35)$ & 0,90 \\
\hline \multicolumn{5}{|l|}{ Children's age: } \\
\hline 5-7 years old & 24 & 7 & Reference & \\
\hline 8-12 years old & 16 & 9 & $0,88(0,18-4,14)$ & 0,87 \\
\hline 13-18 years old & 9 & 3 & $1,69(0,36-7,88)$ & 0,51 \\
\hline \multicolumn{5}{|l|}{ Children's education: } \\
\hline Pre-school & 13 & 4 & Reference & \\
\hline Low level & 33 & 13 & $1,28(0,35-4,66)$ & 0,71 \\
\hline Mid level & 3 & 2 & $2,17(0,26-17,89)$ & 0,47 \\
\hline \multicolumn{5}{|l|}{ Birth order: } \\
\hline First & 24 & 10 & Reference & \\
\hline Not first & 25 & 9 & $0,86(0,29-2,49)$ & 0,79 \\
\hline \multicolumn{5}{|l|}{ Number of children: } \\
\hline 2 children & 28 & 14 & Reference & \\
\hline$>2$ children & 21 & 5 & $2,1(0,65-6,75)$ & $0,21 * *$ \\
\hline \multicolumn{5}{|l|}{ Child-rearing pattern: } \\
\hline Expected & 19 & 4 & Reference & \\
\hline Unexpected & 30 & 15 & $2,38(0,68-8,24)$ & $0,17 * *$ \\
\hline \multicolumn{5}{|l|}{ Father's education: } \\
\hline Advanced & 7 & 0 & & \\
\hline Intermediate & 29 & 16 & NA & \\
\hline Basic & 13 & 3 & & $0,00 * *$ \\
\hline \multicolumn{5}{|l|}{ Mother's education: } \\
\hline Advanced & 10 & 1 & Reference & \\
\hline Intermediate & 22 & 9 & $4,09(0,45-36,81)$ & $0,21 * *$ \\
\hline Basic & 17 & 9 & $5,29(058-48,20)$ & 0,14 \\
\hline \multicolumn{5}{|l|}{ Father's job: } \\
\hline Employed & 46 & 19 & NA & 0,55 \\
\hline Unemployed & 3 & 0 & & \\
\hline \multicolumn{5}{|l|}{ Mother's job: } \\
\hline Employed & 13 & 2 & $3,07(0,62-15,15)$ & $0,17 * *$ \\
\hline Unemployed & 36 & 17 & Reference & \\
\hline \multicolumn{5}{|l|}{ Total family income: } \\
\hline Appropriate to MRW & 20 & 6 & Reference & \\
\hline Below MRW & 29 & 13 & $1,49(0,49-4,59)$ & $0,48^{* *}$ \\
\hline
\end{tabular}

Note: PR: prevalence ratio; CI: confidence interval; *: $\mathrm{p}<0,05 ; * *$ : variables were included in multivariate analysis.

Table 3. The association between steroid therapy and QoL based on parents report

\begin{tabular}{|c|c|c|c|c|}
\hline \multirow{2}{*}{ Characteristics } & \multicolumn{2}{|c|}{ QoL (n=100) } & \multirow{2}{*}{ PR (CI 95\%) } & \multirow{2}{*}{ p value } \\
\hline & Not disturbed & Disturbed & & \\
\hline \multicolumn{5}{|l|}{ Using Steroid } \\
\hline No & 18 & 0 & & \\
\hline Yes & 63 & 19 & NA & $0,02 *$ \\
\hline \multicolumn{5}{|l|}{ Steroid Response } \\
\hline Sensitive & 41 & 9 & Reference & \\
\hline Dependent & 23 & 3 & $1.68(0.35 ; 6.05)$ & 0.46 \\
\hline Resistant & 17 & 7 & $0.53(0,14 ; 1,48)$ & $0.27 * *$ \\
\hline
\end{tabular}

Note: PR: prevalence ratio; CI: confidence interval; *: $\mathrm{p}<0,05 ; * *$ : variables were included multivariate analysis. 
Table 4. The association between steroid therapy with QoL based on children report

\begin{tabular}{|c|c|c|c|c|}
\hline \multirow{2}{*}{ Characteristics } & \multicolumn{2}{|c|}{ QoL (n=68) } & \multirow{2}{*}{ PR (CI 95\%) } & \multirow{2}{*}{$p$ value } \\
\hline & Not disturbed & Disturbed & & \\
\hline \multicolumn{5}{|l|}{ Using Steroid } \\
\hline No & 10 & 2 & Reference & \\
\hline Yes & 39 & 17 & $2.17(0.43 ; 11.02)$ & $0.34^{* *}$ \\
\hline \multicolumn{5}{|l|}{ Steroid Response } \\
\hline Sensitive & 21 & 10 & Reference & \\
\hline Dependent & 14 & 3 & 2.22 (0.52; 9.54) & $0.28 * *$ \\
\hline Resistant & 14 & 6 & 1.11 (0.33; 3.75) & 0.87 \\
\hline
\end{tabular}

Note: PR: prevalence ratio; CI: confidence interval; *: $\mathrm{p}<0,05 ; * *$ : variables were included in multivariate analysis.

\section{Discussion}

In this study, seventy-seven percent (77\%) of the subjects were boys. This study have the same result with other studies that showed mostly NS patients were boys (71 - 80\%) $[7,8,9]$. The most frequent incidence of NS in children is 2- 6 years [1,2]. In this study, the most frequent age group was 2-4 years old (32\%), followed by 5-7 years old (31\%).

In this study, there were $19 \%$ disturbed QoL based on parent's and children's report. Previous study in Yogyakarta using The Netherland Organization for Applied Scientific Research Academical Medical Centre Child Quality of Life (TACQOL) for NS patient with age 6-15 years old showed that $12.8 \%$ of NS children had poor QoL based on parents reports and $18.5 \%$ based on children's reports [5]. This difference can be explained due to the use of different design, method, instrument, age-grouping, inclusion and exclusion criteria. The number found in this study is relatively larger because Dr. Cipto Mangunkusumo Hospital is a national referral hospital with more variety and complex cases. Although the results were different but the disturbance in QoL happened within the range of $12-19 \%$. The magnitude of this incidence showed that this problem needs to be addressed in the management of NS patients.

This study showed that the age of 5-7 years old and 1318 years old were risk factors for disturbed QoL with $\mathrm{p}<0,05$. This association can be explained as the patient entering their teenage years, which is a transition period from childhood to adulthood. This period is marked by the beginning of puberty, sexual and social identification, and the feeling of solidarity among their peers. At this vulnerable period, a chronic disease such as NS may become a stigma and affect child's independency, social function, relation with peer group, self esteem, mood, and cognition [10].

If we divide according to age subgroups, in the age of 2-4 years old, the most affected was emotional domain; in subgroup 5-7 and 8-12 years old, school domain was most affected, and in subgroup 13-18 years old, emotional and school domains were most affected. In the pre-school age, a child must have a basic trust and self autonomy, but NS patient who experiences disturbance in physical condition due to relapse of disease or steroid use, might fail to achieve self autonomy. At this age, a child wants to try new ability which can be achieved through the practice of eating, bathing, and daily activities, but the environment will not give enough opportunities because of his illness. This resulted in disappointment of the child and will affected his QoL [11].

Based on children's report, significant association was found between the level of the father education and the QoL $(p<0,01)$. This result supported by other study in Thailand [12] which found that the education level of the father significantly affect the QoL of the child.

Based on the parents reports, we found that low socioeconomic status was risk factor for a disturbance in QoL. This result was also supported by other study that reported almost $84 \%$ patient with low socio-economic status showed that poverty was related to chronic disease which was a contributor to the high prevalence of behavior disorder [13]. This explained how a low socio-economic condition would affect the QoL. Another study found a correlation between socio-economic status and the QoL $[14,15]$.

Based on parents report, significant association was found between the use of steroid and QoL. Steroid has many side effects, physically such as development disorder, hypertension, obesity, cataract, and behavior disorder [7]. The use of both short- or long-term steroid was a major contributor in causing behavior and psychosocial disorder [16]. Previous study found that children with sensitive steroid NS were experiencing various problems such as anxiety, depression, and increase aggression during high dose prednisone therapy for treating their relapse [7]. In this study, it was suspected that the use of steroid was a risk factor of disturbance in QoL in NS child.

Parents would limit their children's social interaction as an effort to reduce the risk of infection. These factors significantly affect body image and self esteem development which would contribute in child's isolation from social environment [17]. Meanwhile, the significant association between the duration of illness and QoL can be explained that the duration of illness would prolong the child sickness, including admission to hospital, relapse, and longer use of steroid [18].

In this study, some variables based on parents reports were included in the multivariate analysis, such as children's age, children's education, father's education, total family income under MWR, and response steroid therapy, subsequently, had risk to cause a disturbance in QoL. Even though the variables response to steroid therapy mentioned before have insignificant $\mathrm{p}$ value and confidence interval, they were still put in consideration and attention 
because from the previous study, child-rearing pattern was an important factor related to children's QoL [4].

Disturbance in QoL can be influenced by many factors such as parent's factor, education, total family income, child's factor, and environment factors [3,4,10]. In this study, children's reports showed that, number of children, child-rearing pattern, father's education, mother's education, mother's job, and total family income under MWR, subsequently, had risk to cause a disturbance in QoL. The multivariate analysis results showed that the risk factor of disturbed in QoL are low level education status of the father and response to use of steroid in parent's report, and child-rearing and total family income under MWR in children's report. Total family income play a role for developing QoL of children. High total family income may contribute to increase QoL, while low total family income may contribute to decrease QoL. Child-rearing pattern is an important family variable in psychosocial development of children that determine QoL Child-rearing pattern be influenced by culture, religion, level of education, and socio-economic condition [12,17]. This study showed that duration of illness had a significant association with a disturbance in QoL based on parents and children's report $(p<0.05)$. Long period duration of illness could cause problems for parents, family, the patient, and community. The parents leave their job and they have to prepare their activities and times for take care the child. For children, it cause decrease of chance for schooling, playing, or other activities with other children, and also for family economic because of increase budgeting [8,13,17].

Limitation of this study, the samples were not homogenous on steroid response of NS, but we were still able to perform analysis and conclude the results. This study only capture a moment and not evaluate the patients but the results can be a reference to many studies afterward.

In conclusion, a disturbance in QoL of NS children was found $19 \%$ and the risk factors were children age in subgroup 5-7 years old and 13-18 years old, low socio-economic status, low level education of the father, unexpected child-rearing pattern, duration of illness, and the use of steroid. In the management of NS children, it is suggested to develop a team consists of pediatrician, child psychiatrist, psychologist, and social worker, by creating a module of management of NS in children by considering medical judgement and conditions that will affect their QoL.

\section{Conflicts of Interest}

The authors affirm no conflict of interest in this study.

\section{References}

[1] Gipson DS, Massengill SF, Yao L, Nagaraj S, Smoyer W, Mahan JD, et al. Management of childhood onset nephrotic syndrome. Pediatrics. 2009; 124: 747-57.

[2] Trihono PP, Alatas H, Tambunan T, Pardede SO. Konsensus tata laksana sindrom nefrotik idiopatik pada anak. 2nd ed. UKK Nefrologi IDAI, Jakarta.2012, p.1-19.

[3] McKenna AN, Keating LE, Vigneux A, Stevens S, Williams A, Geary DF. Quality of life in children with chronic kidney diseasepatient and caregiver assessments. Nephrol Dial Transplant. 2006; 21: 1899-905.

[4] Ruth EM, Landolt MA, Neuhaus J, Kemper MJ. Health-related quality of life and psychosocial adjustment in steroid-sensitive nephrotic syndrome. J Pediatr. 2004; 145: 778-83.

[5] Simatupang DF, Damanik MP, Sadjimin T. Perbedaan tingkat kualitas hidup anak dengan sindrom nefrotik primer kelainan minimal dan bukan kelainan minimal di RSUP Dr. Sardjito Yogyakarta. Sari Pediatri. 2007; 9: 220-6.

[6] Varni JW, Burwinkle TM, Katz ER, Meeske K, Dickinson P. 2002. The PedsQL* in pediatric cancer: Reliability and validity of the Pediatric Quality of Life Inventory* Generic Core Scales, Multidimensional Fatigue Scale, and Cancer Module. Cancer. 94, 2090-106.

[7] Soliday E, Grey S, Lande M. Behavioral effects of corticosteroids in steroid-sensitive nephrotic syndrome. Pediatrics. 1999; 104: e51.

[8] Soliday E, Kool E, Lande MB. Family environment, child behaviour, and medical indicators in children with kidney disease. Child Psychiatry Hum Develop. 2001; 31: 279-95.

[9] Wong W. Idiopathic nephrotic syndrome in New Zealand children, demographic, clinical features, initial management and outcome after twelve-month follow-up: results of a three-year national surveillance study. J Paediatr Child Health. 2007; 43: 337-41.

[10] Devinsky O, Westbrook L, Glassman M, Perrine K, Camfield C. Risk factors for poor health-related quality of life in adolescents with epilepsy. Epilepsia. 1999; 40: 1715-20.

[11] Newton D,. Kaplan \& Sadock's Comprehensive Textbook of Psychiatry. 9th ed. Lippincott Williams \& Wilkins. Philadelphia. 2009; p.838-47.

[12] Jirojanakul P, Skevington SM, Hudson J. Predicting young children's quality of life. [abstract] Soc Sci Med. 2003; 57: 1277-8.

[13] Guha P, De A, Ghosal M. Behavior profile of children with nephrotic syndrome. Indian J Psychiatry. 2009; 51: 122-6.

[14] Upton P, Eiser C, Cheung I, Hutchings HA, Jenney M, Maddocks A,et al. Measurement properties of the UK-English version of the Pediatric Quality of Life Inventory 4.0 (PedsQLTM) generic core scales. Health Qual Life Outcomes. 2005; 3: 22.

[15] Gkoltsiou K, Dimitrakaki C, Tzavara C, Papaevangelou V, Varni JW, Tountas Y. Measuring health-related quality of life in Greek children: psychometric properties of the Greek version of the Pediatric Quality of Life InventoryTM 4.0 Generic Core Scales. Qual Life Res. 2008; 17: 299-305.

[16] Neuhaus TJ, Langlois V, Licht C. Behavioural abnormalities in children with nephrotic syndrome-an underappreciated complication of standard treatment? Nephrol Dial Transplant. 2010; 25: 2397-9.

[17] Mehta M, Bagga A, Pande P, Bajaj P, Srivastava RN. Behavior problem in nephrotic syndrome. Indian Pediatr. 1995; 32: 1281-6.

[18] Gipson DS, Selewski DT, Massengill SF, Wickman L, Messer KL, Herreshoff E, et al. Gaining the PROMIS perspective from children with nephrotic syndrome: a Midwest pediatric nephrology consortium study. Health Qual Life Outcomes. 2013; 11: 1-9. 